\title{
Assessment of Undergraduate Students in Tooth Extraction Competence A Cohort Study
}

\author{
Urzinger, Sebastian
}

http://hdl.handle.net/10026.1/16696

10.1111/eje.12638

European Journal of Dental Education

Wiley

All content in PEARL is protected by copyright law. Author manuscripts are made available in accordance with publisher policies. Please cite only the published version using the details provided on the item record or document. In the absence of an open licence (e.g. Creative Commons), permissions for further reuse of content should be sought from the publisher or author. 
Title

Assessment of Undergraduate Students in Tooth Extraction Competence - A Cohort Study

K. Ali ${ }^{1}$, HS Qazi², K Siddiqi ${ }^{3}$, R Glanville ${ }^{4}$

${ }^{1}$ Professor of Dental Education/ Honorary Consultant in Oral Surgery, University of

Plymouth Peninsula Dental School

2Head, IM\&DC, Islamabad Pakistan

3Associate Professor in Oral Surgery, IM\&DC, Islamabad Pakistan

${ }^{4}$ Assessment Psychometrician, University of Plymouth Peninsula Medical School

Corresponding Author:

\section{Kamran Ali (First / Corresponding Author)}

PhD MMEd BDS (Hons) FDSRCS FCPS FFDRCSI FDSRCPS FFDTEd PFHEA

National Teaching Fellow

Professor of Dental Education/ Consultant in Oral Surgery, University of Plymouth Peninsula Dental School

Room C504 Portland Square

Drake Circus, University of Plymouth

Plymouth Devon PL4 8AA

United Kingdom

Email: kamran.ali@plymouth.ac.uk

Tel: (+44) (0) 1752586768

Fax:(+44) (0) 1752586788 


\section{Abstract}

Aim: The aim of the study was to determine the value of the number of patient encounters and tooth extractions on the competence of final-year Bachelor of Dental Surgery (BDS) students.

Methods: Following ethics approval, the study employed purposive sampling to enrol final year BDS students and assess their competence longitudinally over a full academic year. Students were assessed periodically on four separate occasions after they had gained experience in performing 15, 40, 70 and 100 patient encounters involving tooth extractions.

Results: There were 177 students with complete profiles completing the tooth extraction assessments including 31 males (18\%) and 146 females (82\%). The age range of participants was 22 to 24 years (mean=21.92; median=22). The total number of assessment data points available for the four assessments was 1062. A chi-square test was carried out of the hypothesis that competence in tooth extraction increases with increasing exposure to patients. Students in Group 100 were most likely to pass the competency, while students in Group 15 were most likely to fail. There was a statistically significant variation in the proportion of 'Below Standard', 'Meets Standard' and 'Exceeds Standard' judgements awarded to students with differing levels of prior experience $(p<0.001)$. Therefore, the hypothesis was accepted. Analysis of assessment results for differential performance of students by gender did not show significant differences.

Conclusions: The results of this study show a positive relationship between the number of tooth extractions performed and competence of final year dental students. Over $90 \%$ students achieved competence after performing 100 patient encounters. Although competence in tooth extractions a linear relationship with experience of the participants in this study, the data was collected from a single cohort of students, at one institution, and further multi-institution studies involving several cohorts are required to further explore the value of increased experience.

Key Words: Competence, dental students, tooth extraction, undergraduate 


\section{Introduction}

Tooth extraction is a fundamental skill in undergraduate dental programs. Dental students are expected to be competent in performing uncomplicated tooth extractions prior to graduation as outlined in the profile and competences for the graduating European dentist. ${ }^{1}$ Competence in tooth extraction is included in the learning outcomes for undergraduate dental programs in the UK and in developing countries. $^{2,3}$ Competence of new dental graduates is defined by abilities essential to begin independent, unsupervised dental practice. ${ }^{4}$ Acquisition of competence in clinical skills requires structured teaching and adequate exposure to patients, providing students opportunities to consolidate their clinical skills. Previous studies have reported marked differences in the structure and delivery of oral surgery teaching in tooth extractions in European dental schools. ${ }^{5,6}$ A previous national survey in the United Kingdom has shown that the average number of non-surgical extractions done by undergraduate students was 51 with a range between $20-116 .{ }^{7}$ On the other hand, dental schools in some developing countries have set much higher clinical targets and students are expected to perform 200 tooth extractions prior to graduation. $^{3,8}$

Although dental students in Europe perceive their teaching and training in tooth extractions to be appropriate, there is a need to further improve oral surgery training to prepare new graduates and enable them to consolidate these skills during their transition into general practice settings. ${ }^{9}$ Apparently, there is lack of consensus on the minimum numerical targets for tooth extraction during undergraduate dental programs 
and dental schools in the UK focus on a competency-based approach, although numerical targets are still identified in most curricula.

The value of number of tooth extractions performed by students during undergraduate education warrants further investigation. Given the potential variations in the learning needs of individual students, it has been suggested that setting a minimum target regarding the number of tooth extractions performed by undergraduate dental students before their competency assessment may not be appropriate. It has also been observed that there is no significant relationship between the total number of teeth extracted and the successful completion of the final assessment. ${ }^{10}$

The aim of the study was to determine the value of the number of patient encounters involving tooth extractions on the competence of undergraduate students. Longitudinal assessments of final year undergraduate dental students at Islamabad Medical and Dental College (IMDC), Islamabad Pakistan were undertaken to determine the relationship between the number of tooth extractions and achievement of competence. 


\section{Methods}

Research Hypothesis:

Competence in performing non-surgical tooth extractions correlates with the number of patient encounters and extractions performed by the students.

Study Design:

Longitudinal cohort study

Setting:

Oral Surgery Department, Islamabad Medical and Dental College (IMDC), Islamabad Pakistan

Sampling Technique:

Purposive sampling.

Participants:

Final year BDS students at IMDC were enrolled in the study and were assessed longitudinally over a full academic year.

Assessment Frequency and Criteria:

Students were assessed periodically on four separate occasions after they had performed 15, 40, 70 and 100 patient encounters involving tooth extractions.

Tooth extraction assessment was based on six sub-components, namely 1) position of the operator and patient; (2) selection of elevators and luxators; (3) selection of forceps; (4) use of non-dominant hand; (5) extraction technique; and (6) postextraction socket management. Students performance for each of the six sub- 
components was graded as: Exceeds standard (ES); Meets standard (MS); or Below standard (BS). The assessment criteria and scoring structure are provided in the appendix and have been reviewed during inspection of the institution by the regulator as well as by the external examiner.

\section{Data Collection:}

Assessment data for each participant was recorded on purposefully designed pro forma and transferred to Microsoft Excel by a designated administrator. If a participant performed more than one tooth extraction in a single patient encounter, the lowest performance was used to grade competence. Accuracy of the data was checked by two staff members of the faculty.

\section{Data Analysis:}

Data was analysed using RStudio (version 1.3.959) incorporating $R$ version 4.0.2. ${ }^{11}$ Chi-squared tests of independence were carried out for each assessment subcomponent and experience group. Chi-squared tests are subject to potential problems caused by zero or near-zero cell counts. To circumvent such problems all p-values were estimated by Monte Carlo simulation with 1,000,000 replicates.

\section{Research Ethics:}

Ethics approval for the study was gained from the institutional review board (IRB) vide letter no. IMDC/DS/IRB/164 dated 19th December 2018). 


\section{Results}

There were 177 students with complete profiles completing the tooth extraction assessments including 31 males (18\%) and 146 females (82\%). The age range of participants was 22 to 24 years (mean=21.92; median=22). The results are summarised in Table 1. The total number of assessment data points available for the four assessments was 1062 .

Table 1: Judgement distribution

\begin{tabular}{rrrrrrrr}
\hline Group & $\begin{array}{r}\text { Judgements } \\
(\mathrm{N})\end{array}$ & $\begin{array}{r}\text { Exceeds } \\
\text { Standard }\end{array}$ & $\begin{array}{r}\text { Exceeds } \\
\text { Standard } \\
\text { (prop) }\end{array}$ & $\begin{array}{r}\text { Meets } \\
\text { Standard }\end{array}$ & $\begin{array}{r}\text { Meets } \\
\text { Standard } \\
\text { (prop) }\end{array}$ & $\begin{array}{r}\text { Below } \\
\text { Standard }\end{array}$ & $\begin{array}{r}\text { Below } \\
\text { Standard } \\
\text { (prop) }\end{array}$ \\
\hline 15 & 281 & 0 & 0.00 & 201 & 0.71 & 80 & 0.28 \\
40 & 264 & 4 & 0.02 & 226 & 0.86 & 34 & 0.13 \\
70 & 258 & 5 & 0.02 & 219 & 0.85 & 34 & 0.13 \\
100 & 258 & 16 & 0.06 & 221 & 0.86 & 21 & 0.08 \\
All & 1062 & 25 & 0.02 & 867 & 0.82 & 169 & 0.16 \\
\hline
\end{tabular}

A graphical representation of assessment results after 15, 40, 70 and 100 patient encounters involving tooth extractions is depicted in Figure 1 


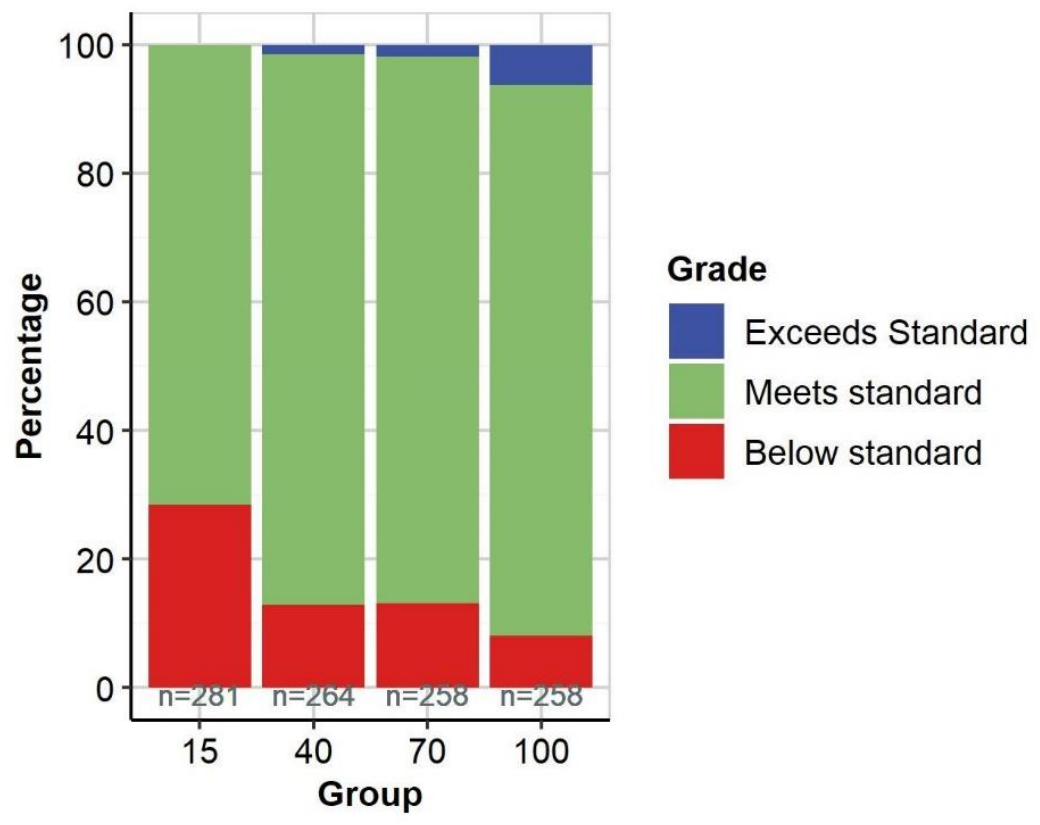

Figure 1 Distribution of judgements of tooth extraction assessments

\section{Chi-Squared Analysis}

A chi-square test was carried out of the hypothesis that competence in tooth extraction increases with increasing exposure to patients. The $p$-value of $<0.001$ indicates that there is statistically significant variation in the proportion of 'Below Standard', 'Meets Standard' and 'Exceeds Standard' judgements awarded to students with differing levels of prior experience and so the hypothesis can be accepted.

By calculating the chi-square residual values, the level of variation across each cohort group and the judgements awarded can be viewed as shown in Table 2. Positive residuals indicate that the group was more likely to achieve that particular judgement than would be expected if there were no relationship between group and grade awarded. It can be seen that, when judgements across all sub-components are 
considered, students in Group 15 are more likely to receive a 'Below standard' judgement and students in Group 100 are more likely to receive an 'Exceeds standard' judgement.

Table 2: Chi-square analysis residual values (all sub-components)

\begin{tabular}{rrrr}
\hline Group & Exceeds Standard & Meets Standard & Below Standard \\
\hline 15 & -2.573 & -1.889 & 5.268 \\
40 & -.0890 & 0.699 & -1.242 \\
70 & -0.438 & 0.563 & -1.107 \\
100 & 4.024 & 0.701 & -3.135 \\
\hline
\end{tabular}

Students with a 'Below Standard' judgement in more than one sub-components were deemed to have failed the tooth extraction component of the assessment. Table 3 provides a breakdown of the component grades by cohort (number and proportion of grades awarded).

Table 3: Grade distribution of participants

\begin{tabular}{rrrrrr}
\hline Group & Judgements & Pass & Pass (prop) & Fail & Fail (prop) \\
\hline 15 & 47 & 26 & 0.55 & 21 & 0.45 \\
40 & 44 & 35 & 0.80 & 9 & 0.20 \\
70 & 43 & 32 & 0.74 & 11 & 0.26 \\
100 & 43 & 39 & 0.91 & 4 & 0.09 \\
All & 177 & 132 & 0.75 & 45 & 0.25 \\
\hline
\end{tabular}


A chi-square test was carried out of the hypothesis that competence in tooth extraction skill increases with increasing exposure to patients. As shown in Table 4, the p-value of 0.001 indicates that there is statistically significant variation in the proportion of 'Pass' and 'Fail' grades awarded to students with differing levels of prior experience and so the hypothesis can be accepted.

Table 4: Chi-square analysis (overall grade)

\begin{tabular}{llllc}
\hline Factor & $\begin{array}{l}\text { Degrees of } \\
\text { Freedom }\end{array}$ & Sample size & $\begin{array}{l}\text { Chi-Square } \\
\text { value }\end{array}$ & p-value \\
\hline Group & 3 & 177 & 15.661 & 0.001 \\
\hline
\end{tabular}

By calculating the chi-square residual values, the level of variation across each cohort group and the overall grades awarded can be viewed as shown in Table 5. It can be seen that students in Group 100 were most likely to pass the assessment, while students in Group 15 were most likely to fail.

Table 5: Chi-square analysis residual values (overall grade)

\begin{tabular}{rrr}
\hline Group & Pass & Fail \\
\hline 15 & -1.529 & 2.618 \\
40 & 0.382 & -0.654 \\
70 & -0.012 & 0.021 \\
100 & 1.224 & -2.097 \\
\hline
\end{tabular}


Analysis of assessment results for differential performance of students by gender did not show significant differences between males and females $(p>0.05)$ as shown in Table 6.

Table 6: Differential performance of participants based on gender

\begin{tabular}{|c|c|c|c|c|c|c|}
\hline Group & $\begin{array}{c}\text { Number of } \\
\text { students } \\
\mathbf{( N )}\end{array}$ & $\begin{array}{c}\text { Males, N and } \\
\text { proport of } \\
\text { the cohort }\end{array}$ & $\begin{array}{c}\text { Females, N } \\
\text { and prop of } \\
\text { the cohort }\end{array}$ & $\begin{array}{c}\text { Males } \\
\text { passing, N } \\
\text { and prop of } \\
\text { males }\end{array}$ & $\begin{array}{c}\text { Females } \\
\text { passing, N and } \\
\text { prop of } \\
\text { females }\end{array}$ & p-value \\
\hline All & 177 & $31(0.18)$ & $146(0.82)$ & $22(0.71)$ & $110(0.75)$ & 0.651 \\
\hline Group 15 & 47 & $9(0.19)$ & $38(0.81)$ & $2(0.22)$ & $24(0.63)$ & 0.059 \\
\hline Group 40 & 44 & $8(0.18)$ & $36(0.82)$ & $6(0.75)$ & $29(0.81)$ & $>0.999$ \\
\hline Group 70 & 43 & $6(0.14)$ & $37(0.86)$ & $6(1.00)$ & $26(0.70)$ & 0.178 \\
\hline Group 100 & 43 & $8(0.19)$ & $35(0.82)$ & $8(1.00)$ & $31(0.89)$ & 0.576 \\
\hline
\end{tabular}




\section{Discussion}

This is perhaps the first study that describes longitudinal assessment of tooth extraction competency in an undergraduate dental program from a developing country. Delivery of tooth extraction teaching for BDS students at our institution started in the pre-final year and they receive clinical exposure shadowing final year students throughout the year. Once students progress to their final year, they undertake tooth extractions under supervision of faculty staff.

The precise stage at which tooth extraction teaching is introduced in undergraduate dental curricula will largely depend on the curriculum model at individual dental institutions. Early clinical exposure may offer greater opportunities to consolidate their clinical skills and also develop team-working skills in clinical environments. ${ }^{12}$ Nevertheless, patient safety is a primary concern especially with irreversible operative procedures including tooth extractions. Institutions must ensure that students receive appropriate pre-clinical training in simulated settings and are also assessed appropriately before they undertake tooth extractions on patients.

Teaching and assessment of competence in tooth extractions is generally more straight forward in a simulated environment as the assessments can be standardised and student performance can be gauged in a risk-free environment. It also allows the dental schools to ensure that students demonstrate basic skills in a pre-clinical environment before undertaking irreversible operative procedures on patients, thereby providing a safety net to protect the public. These advantages of pre-clinical assessments have contributed to the growing trend of assessment in a simulated environment in European dental schools. ${ }^{13}$ 
Historically, dental institutions in developing countries have not provided structured teaching and assessments of tooth extractions in simulated environment. However, there is increasing recognition of the benefit of simulated learning environments and many institutions, including our own, are developing structured pre-clinical teaching in tooth extractions. Hopefully, these measures are likely to improve the learning experiences of our students further.

Our results show that differences in students' performance after 40 and 70 patients encounters were not statistically significant. These observations are potentially related to a combination of factors including difficulties in standardisation of patients requiring tooth extractions; weaknesses in assessor calibration; and remediation of underperforming students. One of the main challenges of clinical assessment of tooth extraction competency is related to difficulties in standardising patients. A number of patient-related factors can complicate tooth extractions including medical history, patient co-operation, degree of mouth opening, presence of acute infection, location, and position of the tooth be extracted. In addition, several factors, which may increase difficulty-level of tooth extractions, may not be identified consistently during preoperative clinical and routine radiographic assessment. Such factors may include bone elasticity, presence of accessory roots, and concrescence. Moreover, tooth fracture is more likely to be observed during extractions of maxillary first premolar and molars. ${ }^{14}$ Given these variations in the difficulty-level of tooth extractions, it is not unusual that otherwise competent students may face difficulties in extracting teeth due to the lack of standardisation and complicating factors. 
Standardisation of patients in our study was largely limited to initial triage by clinical academic staff to determine suitability for undergraduate students. Patients requiring surgical removal of teeth based on clinical and radiographic evaluation were excluded for all assessments as were retained roots and deciduous teeth. Subsequently the patients were allocated to students randomly. It may be possible to grade extraction difficulty by triangulating complicating factors in patient's medical history (such as ASA classification) and tooth-related factors such as dilaceration, hypercementosis, angulation, of the tooth, and root ankylosis etc. However, such an approach would require developing an appropriate triage system and may have resource implications.

The assessments of the participants in this study were carried out over a period of nine months. The assessments were conducted when individual students had completed their individual targets for each of the four assessments i.e., 15, 40, 70 and 100 patient encounters. . The dates for assessment of individual students were agreed between the support staff collating clinical activity data and the student. We used a criterion-referenced assessment for competence in tooth extraction. ${ }^{15}$ External validity of the assessment was furnished through review of the assessment criteria by the regulator and external examiner. ${ }^{16}$

The assessment team consisted of five academic oral surgeons based at the university with a minimum of three years teaching experience. Calibration of the assessors was led by the head of oral surgery department. Assessment results and written feedback from 10 students of a previous cohort were used to calibrate the assessors and reach a consensus on use of marking criteria for each of the six components of competency assessment as described in the methods section. Initially 
assessor calibration was carried out prior to commencement of the study and was repeated after 4 months. Each participant was assessed by a single assessor.

On reflection, it was felt that improvements in calibration could be achieved by assessing live performance of candidates. Currently we are evaluating various options for calibration including: (a) faculty members acting as students to carry out tooth extractions in simulated settings; (b) live assessment of 8-10 students working in routine exodontia clinics as a group of assessors; (c) developing a bank of videorecorded performances by students undertaking extractions. ${ }^{17}$ Moreover, the assessors need to be encouraged to use the full range of scores appropriately. Although assessors provided individual feedback to all students after each assessment, inconsistencies were noted in the remediation of underperforming students. It was agreed that formal remediation would need to be provided to all underperforming students before they attempt further tooth extractions.

Although competence in tooth extractions a linear relationship with experience of the participants in this study, the data was collected from a single cohort of students, at one institution, and further multi-institution studies involving several cohorts are required to further explore the value of increased experience. Shortage of suitable cases for undergraduates in developed countries has been suggested to be one of the limits to develop confidence. ${ }^{18}$ Therefore, it may be inappropriate to recommend a minimum number of extractions which should be performed by undergraduate dental students and local circumstances at individual institutions may need to be considered to inform the clinical targets. The number of extractions performed by students during undergraduate education is only one of several elements which may contribute to enhancing their competence. Dental academics may use feedback from relevant 
stakeholders including the students and faculty to improve the quality of their teaching and assessment strategies.

Dental programs have a limited duration and there is a need to moderate the expectations regarding the "grain-size" of competence that may be expected from new graduates. ${ }^{19}$ Although teaching of dental students using a competency-based framework appears to realistic, evidence from the literature suggests that experience may not be a reliable predictor of competency. ${ }^{20}$ Consistency in performance measured by longitudinal assessment under different contexts (breadth) may be required to establish competence. ${ }^{21}$ The process of developing the capacity for independent practice typically extends well beyond the temporal confines of undergraduate university education and a new dental graduate may take several years to consolidate their skills . ${ }^{4}$ Equally, patient availability, shortage of supervisory staff and other logistic issues may limit student experience in tooth extractions. Ultimately, institutional circumstances may influence the training model and competence assessments of students. 


\section{Conclusions}

The results of this study show a positive relationship between the number of tooth extractions performed and competence of final year dental students. Over $90 \%$ students achieved competence after 100 patient encounters. Although competence in tooth extractions a linear relationship with experience of the participants in this study, the data was collected from a single cohort of students, at one institution. Given the limitations of this study, further multi-institution studies involving several cohorts are required to further explore the value of increased experience.

\section{Conflict of Interest}

None of the authors / co-authors have any conflict of interest to declare

\section{Data Availability Statement}

The data that support the findings of this study are available on request from the corresponding author. The data are not publicly available due to privacy or ethical restrictions.

\section{Acknowledgements}

The authors would like to thank all staff and students who participated in this study. 


\section{References}

1. Cowpe J, Plasschaert A, Harzer W, Vinkka-Puhakka H, Walmsley AD. Profile and competences for the graduating European dentist-update 2009. Eur J Dent Educ. 2010;14(4):93-202.

2. GDC. Preparing for practice. Dental team learning outcomes for registration. London: General Dental Council. 2015.

3. Pakistan Medical and Dental Council: BDS Regulations. http://www.pmdc.org.pk/Regulation/RegulationsforBDS/tabid/116/Default.aspx Accessed August 18, 2020

4. Chambers DW, Gerrow JD. Manual for developing and formatting competency statements. J Dent. Educ. 1994;58(5):361-66.

5. Brand HS, Van Der Cammen CC, Roorda SM, Baart JA. Tooth extraction education at dental schools across Europe. BDJ open. 2015;1(1):1-6.

6. Macluskey M, Durham J. Oral surgery undergraduate teaching and experience in the United Kingdom: a national survey. Eur J Dent Educ. 2009;13(1):52-57.

7. Durham JA, Moore UJ, Corbett IP, Thomson PJ . Assessing competency in dentoalveolar surgery: a 3-year study of cumulative experience in the undergraduate curriculum. Eur J Dent Educ. 2007;11: 200-207.

8. Kerala University of Health Sciences: Bachelor of Dental Surgery Course. http://14.139.185.154/kuhs new/images/uploads/pdf/academic/coursessyllabus/Dental/bds.pdf Accessed August 18, 2020

9. Wilson N. Oral surgery services and training. Brit. Dent. J. 2011;210(3):95-95.

10. Al-Dajani M. Dental students' perceptions of undergraduate clinical training in oral and maxillofacial surgery in an integrated curriculum in Saudi Arabia. $J$ Educ. Eval Health Prof. 2015;12.

11. RStudio Team (2020). RStudio: Integrated Development Environment for R. Studio, PBC, Boston, MA. http://www.rstudio.com/ Accessed August 18, 2020

12. Ali K, Zahra D, McColl E, Salih V, Tredwin C. Impact of early clinical exposure on the learning experience of undergraduate dental students. Eur J Dent Educ. 2018;22(1):e75-80.

13. Stelzle F, Farhoumand D, Neukam FW, Nkenke E. Implementation and validation of an extraction course using mannequin models for undergraduate dental students. Acta Odont Scand. 2011;69(2):80-7. 
14. Hupp MR, Ellis JR, Tucker E. Contemporary oral and maxillofacial surgery. Elsevier Missouri. 6th Edition, 2008: 92-112.

15. Turnbull JM. What is... normative versus criterion-referenced assessment. Med Teach. 1989;11(2):145-50.

16. Hamdy H, Prasad K, Williams R, Salih FA. Reliability and validity of the direct observation clinical encounter examination (DOCEE). Med Ed. 2003;37(3):20512.

17. Sturman N, Wong WY, Turner J, Allan C. Online examiner calibration across specialties. The Clin Teach. 2018;15(5):377-81.

18. Honey J, Lynch CD, Burke FM, Gilmour AS. Ready for practice? A study of confidence levels of final year dental students at Cardiff University and University College Cork. Eur J Dent Educ. 2011;15: 98-103.

19. Ali K, Cockerill J, Zahra D, Qazi HS, Raja U, Ataullah K. Self-perceived preparedness of final year dental students in a developing country- A multiinstitution study. Eur J Dent Educ. 2018;22(4):e745-50.

20. Wimmers PF, Schmidt HG, Splinter TA. Influence of clerkship experiences on clinical competence. Med Educ. 2006;40(5):450-8.

21. Dawson LJ, Mason BG, Bissell V, Youngson C. Calling for a re-evaluation of the data required to credibly demonstrate a dental student is safe and ready to practice. Eur J Dent Educ. 2017;21(2):130. 